\title{
Orientaciones astronómicas en el oppidum oretano del Cerro de las Cabezas (Valdepeñas, Ciudad Real)
}

\author{
Astronomical orientations in the Iberian oppidum of Cerro de las Cabezas \\ (Valdepeñas, Ciudad Real)
}

César Esteban ${ }^{\mathrm{a}}$ y Luis Benítez de Lugo Enrich ${ }^{\mathrm{b}}$

\section{RESUMEN}

Se presenta un análisis arqueoastronómico de la orientación definida por los muros del santuario de entrada del oppidum ibérico Cerro de las Cabezas (Valdepeñas, Ciudad Real), situado en la Oretania septentrional, así como de otros recintos pertinentes para el análisis. El resultado más relevante es que dos de los muros perimetrales del santuario están orientados hacia el amanecer en los equinoccios y en el solsticio de verano respectivamente. Como en otros santuarios ibéricos, se encuentra que la salida del Sol en los equinoccios se produce sobre la cumbre de una de las montañas más distantes del horizonte. También planteamos la posibilidad de que otros muros del mismo santuario puedan estar orientados hacia ortos de varias de las estrellas más brillantes del cielo. Se constata que el eje este-oeste de la trama urbana de la parte meridional del oppidum (donde se localiza un recinto de carácter cultual para algunos autores) se orienta aproximadamente hacia el orto en el solsticio de invierno. Finalmente documentamos un posible alineamiento entre el santuario de entrada, la necrópolis descubierta al este del oppidum y el punto del horizonte donde se produce el orto del solsticio de invierno.

\section{ABSTRACT}

We present an archaeoastronomical analysis of the orientations observed in the entrance-sanctuary and other enclosures at the Iberian oppidum Cerro de las Cabezas
(Valdepeñas, Ciudad Real, Spain), located in the northern Oretania. The most important result of this work is that two of the perimeter walls of the entrance-sanctuary are oriented towards the sunrise, one at the equinoxes and the other at the summer solstice. As in other Iberian sanctuaries, an equinoctial marker is also found. This coincides with the top of one of the most distant mountains of the horizon. The possibility that other walls of the entrance-sanctuary may be oriented to the rising of several of the brightest stars in the sky is also discussed. Moreover, it is found that the east-west axis of the southern part of the oppidum (where an enclosure that some authors have interpreted as a possible sanctuary is located) is oriented approximately toward the sunrise at the winter solstice. Finally a possible alignment between the entrance-sanctuary, a necropolis located at the east and the point of the horizon where the sunrise of the winter solstice occurs is also reported.

Palabras clave: Arqueoastronomía; Santuarios; Cultura Ibérica; Edad del Hierro; Península Ibérica; Castilla-La Mancha.

Key words: Archaeoastronomy; Sanctuaries; Iberians; Iron Age; Iberian Peninsula; Castilla-La Mancha.

\section{INTRODUCCIÓN}

El estudio del movimiento y de los cambios de apariencia de los astros permite establecer se-

\footnotetext{
a Instituto de Astrofísica de Canarias. C/ Vía Láctea s/n. 38205 La Laguna. Santa Cruz de Tenerife y Dpto. de Astrofísica. Facultad de Ciencias. Universidad de La Laguna. Avda. Astrofísico Francisco Sánchez s/n. 38206 La Laguna. Santa Cruz de Tenerife. Correo e.: cel@iac.es http://orcid.org/0000 000252475943.

b Dpto. de Prehistoria y Arqueología, Facultad de Filosofía y Letras. Universidad Autónoma de Madrid. Campus de Cantoblanco. 28049 Madrid y Universidad Nacional de Educación a Distancia. Centro Asociado de Ciudad Real. Aptdo. de Correos 238.13300 Valdepeñas (Ciudad Real). Correo e.: luis.benitezdelugo@uam.es http://orcid.org/0000-0003-2000-6293

Recibido 11-I-2016; aceptado 13-II-2016.
} 
cuencias temporales de distinta duración como el ciclo día-noche, el de las fases de la Luna (origen del mes), o el ciclo del movimiento del Sol (base del año solar). Está claro, y posiblemente así lo ha sido para el ser humano desde la más remota antigüedad, que el ciclo solar anual regula el ciclo vegetativo de la naturaleza, por lo que la ordenación y previsión de las tareas agrícolas y ganaderas pasa, necesariamente, por la familiarización con los movimientos periódicos del Sol sobre la bóveda celeste. La necesidad de un calendario no obedece sólo a razones fundamentales para la supervivencia de una sociedad, como la ordenación de la actividad económica y productiva, sino también a razones religiosas, rituales y como herramienta de demostración de poder y de "control" de la naturaleza por parte de las jerarquías políticas y religiosas. Por medio de la Arqueología y las fuentes escritas sabemos que la cultura ibérica era una sociedad compleja, dominada por una élite principesca, cuyas actividades económicas principales eran la agricultura y la ganadería. Por otra parte, su génesis se debe al contacto directo con culturas orientales como la fenicia y la griega que disponían de calendarios y de un notable conocimiento astronómico (mucho mejor conocidos en el caso del mundo griego). Por todo ello, es posible considerar, como hipótesis de partida, que la cultura ibérica adquirió unos ciertos conocimientos astronómicos, bien por desarrollo propio o por influencia de los colonizadores desde época orientalizante. Es probable que, si los aspectos astrales formaron parte del mundo religioso y ritual ibérico, éstos se vieran incorporados de alguna forma al diseño de sus ciudades, construcciones religiosas y necrópolis, como de hecho se ha constatado en diferentes culturas de la Antigüedad.

El presente trabajo pretende verificar esta hipótesis en la Oretania septentrional. La historiografía tradicional y la investigación actual coinciden en situar al pueblo oretano en diversas zonas de las actuales provincias de Ciudad Real, Albacete y Jaén, a partir de la lectura e interpretación de las fuentes clásicas y de su comparación con los datos toponímicos, epigráficos y arqueológicos. Los oretanos ocuparon un territorio amplio y variado desde el punto de vista geográfico, vertebrado en torno a Sierra Morena, un espacio de excepcional importancia económica durante la Protohistoria y la Edad Antigua de la Península Ibérica. El térmi- no "Oretania septentrional" designa tradicionalmente, con fines meramente utilitarios y connotaciones geográficas (nunca culturales o étnicas), a las comunidades oretanas ubicadas al norte de Sierra Morena, en el área sur de la Meseta meridional (Benítez de Lugo et al. 2004).

\section{CONTEXTO ARQUEOLÓGICO}

En la Oretania septentrional existen varios $o p$ pida objeto de excavaciones arqueológicas sistemáticas. Sólo en Alarcos (Ciudad Real) y Cerro de las Cabezas se han realizado programas de conservación que permiten examinar con detalle y rigor las construcciones exhumadas. Precisamente en estas ciudades se han detectado edificios identificados como santuarios (Almagro Gorbea y Moneo 2000). No se conocen en el territorio oretano septentrional santuarios extraurbanos pero sí otros ubicados en el interior de Sierra Morena, como los jienenses de Collado de los Jardines (Santa Elena) y Cueva de La Lobera (Castellar), utilizados tanto por los oretanos del norte como los del sur por su situación central. El edificio interpretado como santuario en Alarcos es una construcción rectangular de piedra con cuerpo superior de adobes, flanqueado por una calle solada y por otros pavimentos. Este edificio está en buena parte arrasado por la construcción de una gran muralla medieval. Por ello los estudios arqueoastronómicos se han centrado únicamente en las construcciones del Cerro de las Cabezas.

El Cerro de las Cabezas se encuentra ubicado en la margen izquierda del río Jabalón, al sur de La Mancha y de la Meseta Sur (Fig. 1). El asentamiento protohistórico ocupa una superficie aproximada de 14 ha en la ladera oriental de un cerro de una altitud ortométrica de $805 \mathrm{~m}$, con pendientes pronunciadas al norte y oeste, y suaves al este y sur. La posición del asentamiento es claramente estratégica. Está situado en la arteria de comunicación este-oeste que constituye el Jabalón, con hitos de población protohistórica importantes próximos, como Laminium (Alhambra), Cerro Domínguez (Granátula de Calatrava) o Alcubillas, todos en Ciudad Real. Está próximo al paso hacia el valle del Guadalquivir a través del río Despeñaperros, del Guarrizas o del Puerto del Muradal, con el importante hito intermedio del 


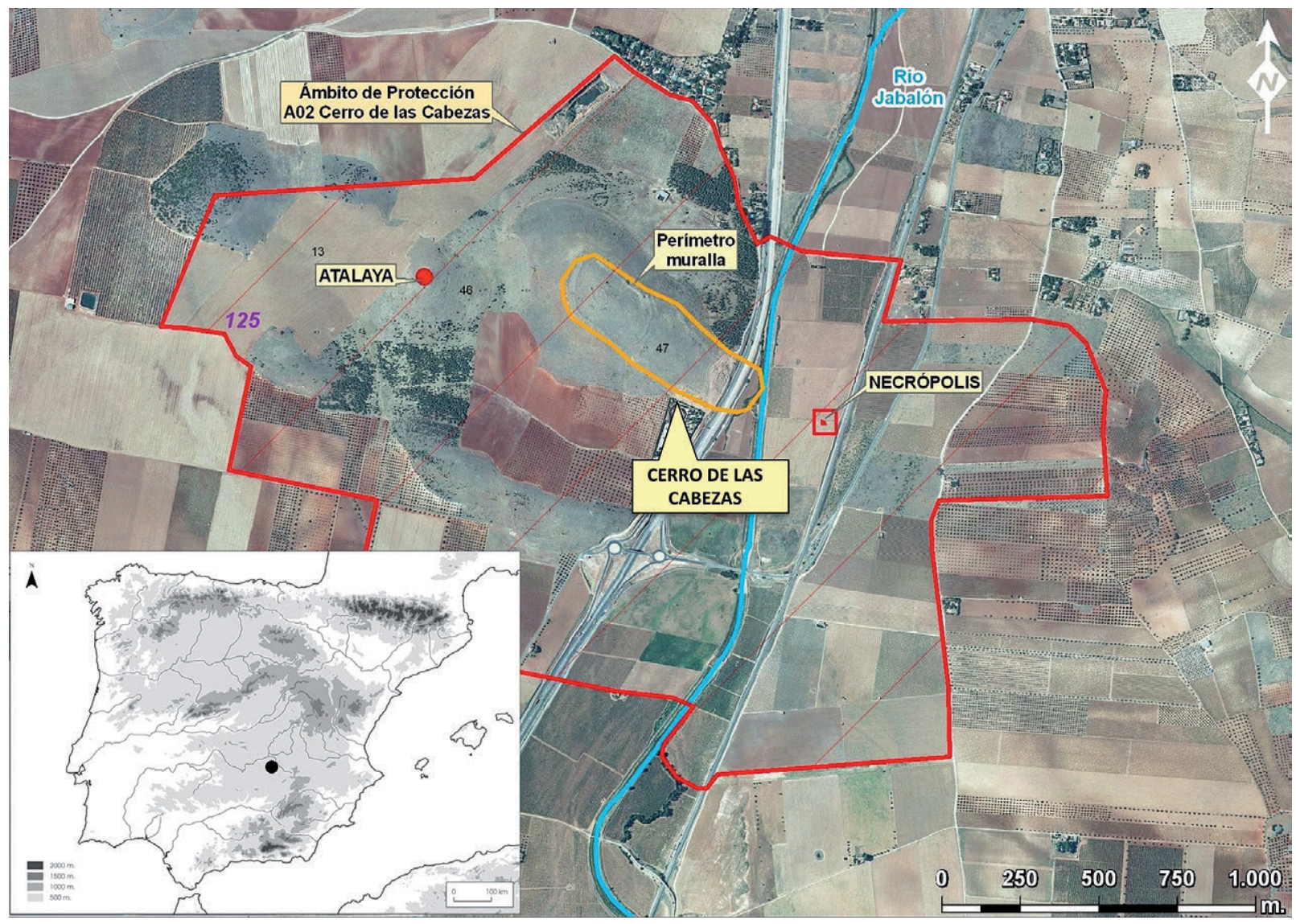

Fig. 1. Localización de la ciudad, atalaya y necrópolis en el ámbito arqueológico de protección "Cerro de las Cabezas" (Valdepeñas, Ciudad Real). Imagen de fondo obtenida del Plan Nacional de Ortofotografía Aérea y rotulada por Jaime Moraleda.

Santuario de Collado de los Jardines. También es significativa su cercanía al corredor natural de La Mancha, que permite la salida del mineral oretano y las relaciones hacia el norte. El yacimiento está en excavación desde 1985, habiéndose puesto al descubierto una notable superficie del asentamiento protohistórico en la parte más baja de la ladera, distinguiéndose varias fases de ocupación, que comprenden la totalidad de la Protohistoria, desde la Edad del Bronce Final hasta el periodo ibérico pleno.

En estas campañas se han detectado tres piezas arqueológicas que parecen representar estrellas, algo desconocido en Alarcos. Un fragmento de placa de terracota con una escena figurativa excisa e incisa muestra una estrella de cinco puntas y una cabeza de ave que picotea una flor de loto (según Benítez de Lugo 2004: 43-44) (Fig. 2A). La se- gunda pieza es un galbo estampillado con la figura de un carnassier o bestia depredadora carnívora, situado bajo dos astros (según Benítez de Lugo 2004: 45-46) (Fig. 2B). Se ha identificado este mismo motivo en una probable urna funeraria en Madridejos (Toledo) (Rodríguez y Palencia 2014: 13). La tercera pieza es un anillo argénteo con un sello decorado con un grifo entre astros (según Benítez de Lugo 2004: 51 y 55) (Fig. 2C).

Se había propuesto una orientación astronómica, pendiente de caracterización, al denominado "santuario de entrada" del Cerro de las Cabezas, enfrentado intramuros a un acceso principal del poblado, al noreste del mismo (Moneo et al. 2001; Benítez de Lugo y Moraleda 2013: 227) (Fig. 3A). Esta dependencia es una especie de capilla perteneciente a una construcción doméstica mayor. Los elementos más interesantes que hay en su interior 

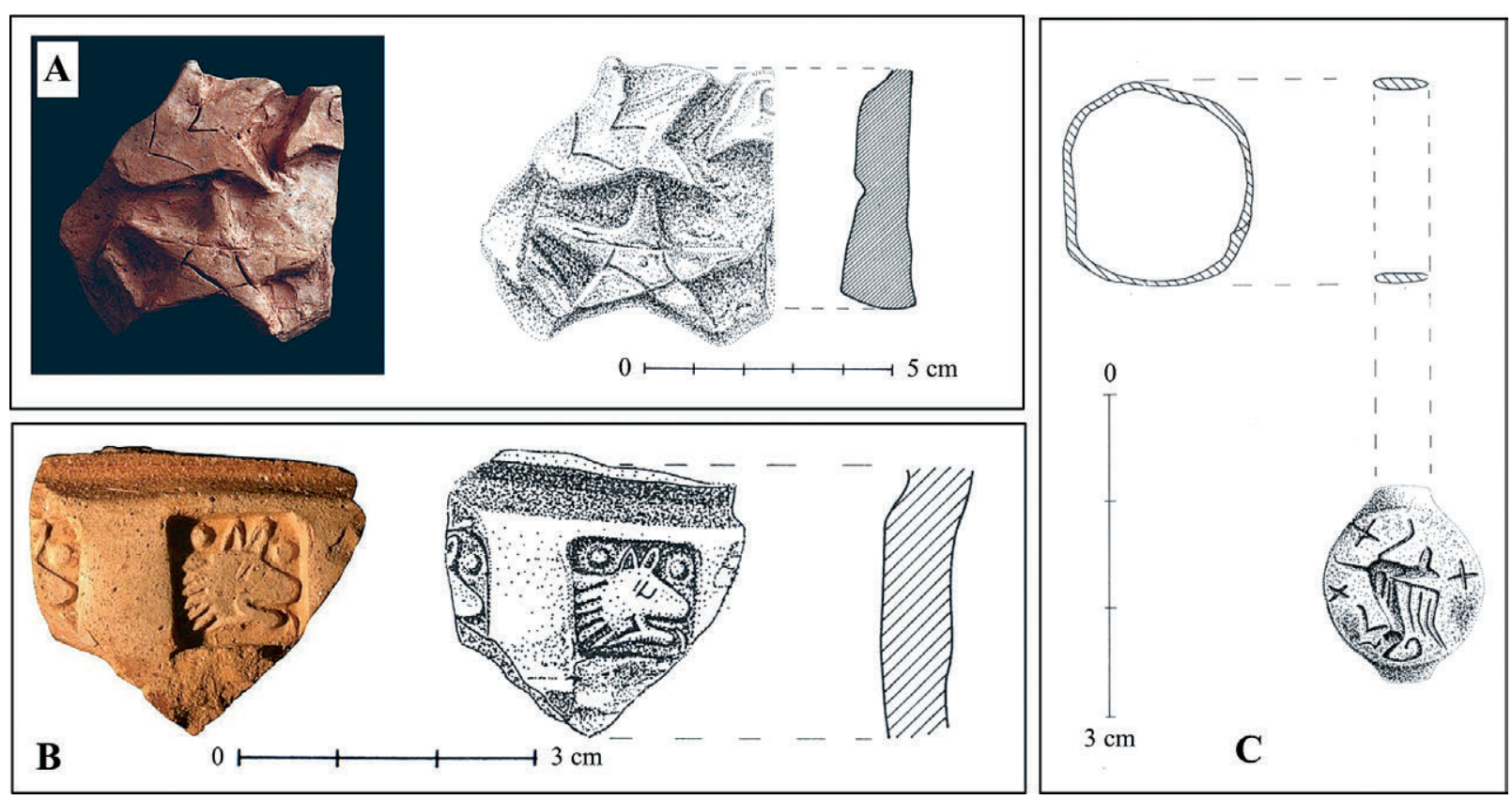

Fig. 2. Cerro de las Cabezas: A. fragmento de placa de terracota con estrella de cinco puntas y cabeza de ave que picotea una flor de loto; B. galbo cerámico con decoración pintada y estampillada que representa un carnassier situado bajo dos astros; C. anillo argénteo con un sello decorado que muestra a un grifo entre astros (según Benítez de Lugo 2004: 43-46, 51 y 55, fotografías Raimundo Campos, dibujos Gabriel Menchén).

son tres irregulares estelas de cuarcita no talladas, que han sido identificadas como betilos. Están hincadas directamente en el suelo de la habitación y calzadas, bajo el nivel del suelo, con piedras pequeñas y medianas. Unas potentes piedras esquineras o guardacantones evitaban que las ruedas de los carros dañasen los expuestos vértices de este edificio religioso, situado a la entrada de la ciudad, en medio del vial de acceso. El conjunto ha sido fechado en el siglo III a.C. En la calle en los alrededores del edificio, se halló una gruesa capa de cenizas de $20 \mathrm{~cm}$ de potencia asociada a cerámicas de diversa tipología con decoración geométrica pintada y estampillada característicamente oretana, fragmentos de piedras volcánicas utilizadas como soleras o volanderas de molinos de mano, pesas de telar cocidas y sin cocer, una ficha, fragmentos amorfos de útiles de hierro, una falcata de hierro bien conservada con acanaladuras en la empuñadura y algunos huesos, así como un cráneo y las astas de un cérvido. Las cenizas mencionadas pueden proceder de la actividad desarrollada en el horno metalúrgico presente en otra de las estancias del edificio (Benítez de Lugo y Moraleda 2013: 228). Dentro de la habitación calificada como santuario se recuperaron objetos habituales en oppida oretanos, como una fusayola, dos tapaderas (una de cerámica de cocina y la otra de cerámica gris, procedente de una pequeña botella decorada con finas bandas de pintura vinosa), unos pocos restos de fauna y una punta de cuchillo. La cerámica asociada, muy fracturada a diferencia de la encontrada en el resto del edificio, responde a la tipología formal y decorativa habitual. Las decoraciones son bícromas (de colores vinosos y engobes anaranjados) y geométricas, organizadas en bandas de líneas, semicircunferencias, dientes de sierra o estampillas. Los bordes son vueltos, de pico de pato y perfiles moldurados, propios de tinajillas y ollas globulares datadas en los siglos IV y III a.C. Destaca un vaso caliciforme de perfil suave en $\mathrm{S}$, característico del periodo ibérico pleno. También había fragmentos de cerámicas grises bruñidas de calidad, correspondientes a platos de perfil hemiesférico con bordes ligeramente apuntados y anillos altos como fondos, y con decoración reticulada o de anillos concéntricos en su interior. Se recuperó 

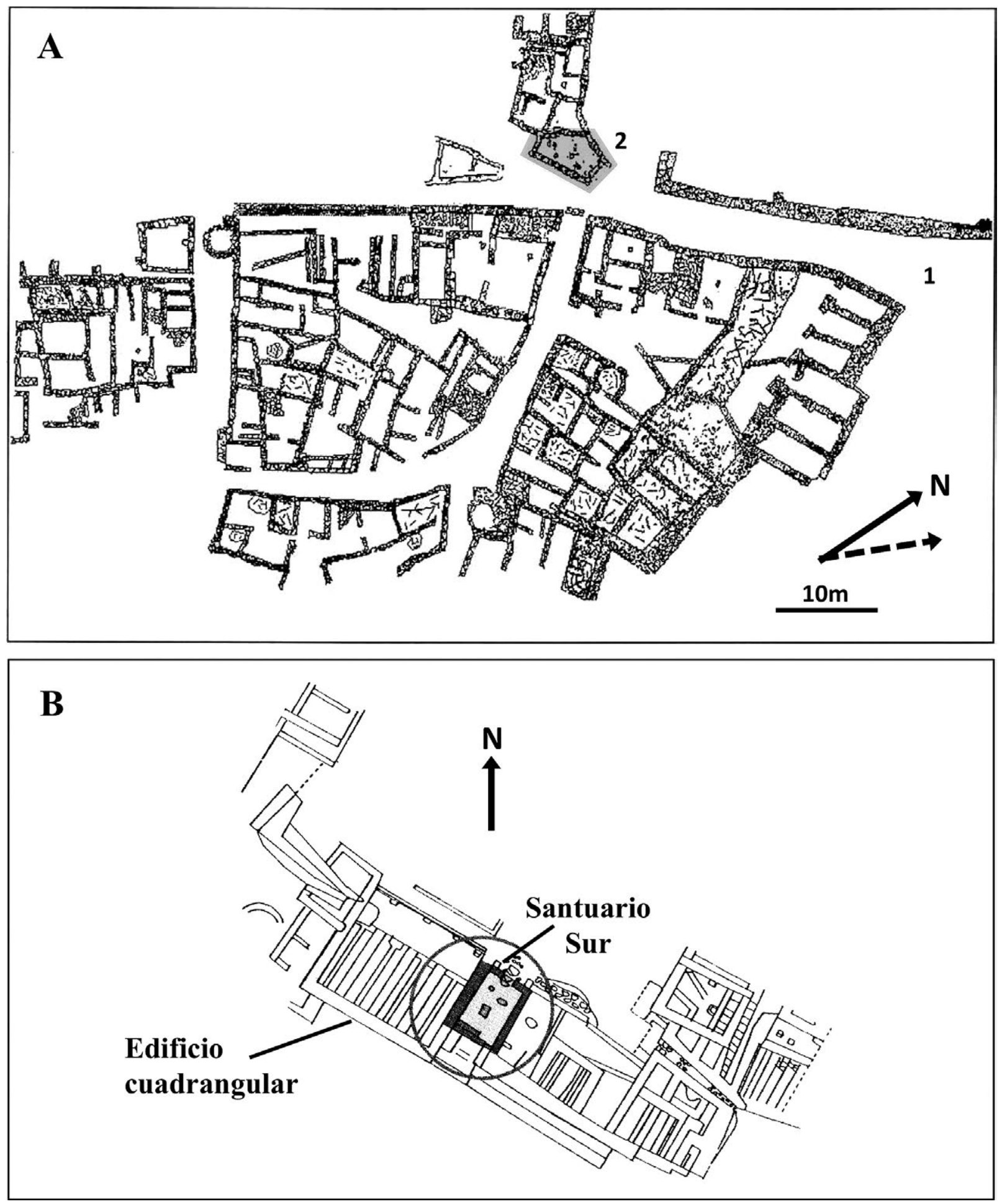

Fig. 3. Cerro de las Cabezas. A. Plano del área urbana próxima a la entrada norte (1) y al santuario de entrada (2 y resaltado con trama gris)(según Moneo et al. 2001: fig. 1). La flecha de trazo continuo señala la dirección real del norte geográfico y la de trazo discontinuo la dirección del norte indicado en el plano original. B. Plano de la muralla meridional, junto a cuyo bastión se adosó la edificación calificada como santuario (según Carmona 2003: 51-53). 
allí mismo un fragmento del labio de un kylix ático de figuras rojas perteneciente al Grupo de Viena 116 (Moneo et al. 2001: 133-134, figs. 5 y 7-10). Es interesante reseñar que la puerta de esta estancia fue tapiada con mampostería y que la forma de su planta es pentagonal y se orienta, en lo más inmediato, hacia la puerta de entrada al oppidum.

Además del santuario de entrada, existe en este poblado otro edificio analizado con motivo de este estudio. Se trata del "Santuario Sur", así denominado por los directores de las excavaciones arqueológicas (Carmona 2003; Vélez y Pérez Avilés, 2008, 2010) (Fig. 3B). En cambio para otros investigadores, adscritos a diferentes universidades, no debe asignársele un carácter cultual o sacro, sino más bien relacionado con el control del almacén ubicado dentro del bastión anejo (García Huerta y Morales 2009: 183; Benítez de Lugo y Moraleda 2013: 233-234 y 236). Esta edificación cuenta con una planta rectangular de $10 \times 4 \mathrm{~m}$, que ha sido fechada a principios del siglo III en base a los materiales asociados: abundantes cerámicas (una urna globular de cerámica común, borde exvasado y decoración pintada geométrica), una piedra de molino, un pequeño cuchillo de hierro afalcatado y diversos materiales orgánicos (cuerdas y esparto carbonizados). Sus muros se levantaron con adobes dispuestos sobre zócalo de mampostería cuarcítica irregular, trabada con barro. Esta estancia se construyó sobre una puerta de corredor de acceso al poblado de $9 \mathrm{~m}$ de largo y 2,30 m de ancho, que resultó cegada al edificar esta estancia. El interior del recinto contaba con un suelo de arcilla apisonada. Todo el interior se revocó con una fina capa de barro que estuvo encalada. En el centro de la habitación se conserva un hogar rectangular de 110 x $80 \mathrm{~cm}$. que presenta un cordón o borde redondeado en su perímetro exterior. En su interior se encontraron carbón y cerámicas quemadas. Cercano al hogar se aprecian los restos de un pequeño horno ovalado. Frente a estas estructuras y adosado al muro sur se conserva un banco o poyo corrido, compuesto por cuarcitas revocadas y encaladas. En la esquina suroeste la fosa de fundación contenía dos pulseras confeccionadas con pequeñas fusayolas envueltas en paños de lino asociadas a cerámicas del siglo IV a.C., lo que ha sido interpretado como un rito fundacional. La estancia fue usada hasta el momento de abandono de la ciudad, tapiándose también su puerta con piedras tras su último uso y quedando todos los materiales en su interior. Este fenómeno se aprecia en muchos otros recintos de la ciudad.

Los excavadores asignan a este lugar un carácter sacro sobre todo a partir del hogar central, su "elemento más significativo" (Vélez y Pérez Avilés 2010: 29) que estaría "orientado astronómicamente" (Vélez y Pérez Avilés 2010: 33), aunque no especifican qué astros guiarían su construcción. Más cercanamente en el espacio, dicho hogar está orientado al poyo frente al cual se encuentra, como otros muchos hogares centrales hallados en otras estancias del poblado para las cuales no se ha defendido ni una orientación astronómica ni un carácter sacro.

El presente artículo es el primer trabajo arqueastronómico realizado hasta la fecha en la Oretania septentrional. Se centra en los santuarios en yacimientos bien conservados, por ser en los que puede detectarse si la astronomía jugó un papel importante en la localización, diseño y orientación de algunas construcciones. Ello estaría en relación directa con el grado de importancia que tuviesen los aspectos celestes en el rito y en la religión de sus constructores, algo que todavía se desconoce.

\section{MÉTODO DE TRABAJO Y OBTENCIÓN DE DATOS}

El trabajo de campo se centró en la medida de la orientación de distintos elementos arquitectónicos de varios edificios del oppidum de Cerro de las Cabezas en algún momento interpretados como de uso cultual, así como de rasgos topográficos destacables del horizonte que les rodea. El instrumental utilizado fue un teodolito, una brújula de precisión, un receptor GPS de navegación y una cámara fotográfica digital.

El santuario de entrada presenta una planta pentagonal irregular, carece de un eje de simetría definido y sus paredes no forman ángulos rectos entre sí, por lo que nos limitamos a medir la orientación de los distintos muros del edificio. El edificio que conforma el denominado "Santuario Sur" es rectangular, y al contrario que el caso anterior, tiene ejes de simetría bien definidos, por los que la orientación de sus muros y sus accesos coincide con las de sus ejes de simetría. 
La orientación (acimut ${ }^{1}$ ) de cada uno de los muros perimetrales de los edificios se midió con la brújula de precisión. El teodolito se colocó en el centro del santuario de entrada y se utilizó para medir las coordenadas horizontales: acimut $(A)$ y altura sobre el horizonte $(h)$, de varios elementos topográficos relevantes del horizonte oriental (el occidental corresponde a la ladera del propio cerro donde se sitúa el yacimiento y no presenta rasgos destacables). Los ángulos horizontales medidos con el teodolito se transformaron a acimutes referidos al norte geográfico mediante medidas de la posición del centro del disco solar cronometradas con el GPS (que también proporciona el Tiempo Universal preciso). Los acimutes de los elementos topográficos seleccionados se compararon con los ángulos horizontales medidos con la brújula para esos mismos puntos y la diferencia promedio nos proporcionó la declinación magnética, que resultó ser de $-2^{\circ 2}$. Esta es la magnitud que hay que sumar algebraicamente para transformar a acimutes los ángulos medidos con la brújula. Posteriormente, con dicho valor de la declinación magnética corregimos las medidas de las orientaciones de los muros del santuario (en Esteban y Escacena Carrasco 2013 una descripción más detallada). A partir del par de coordenadas acimut y altura de los puntos del horizonte medidos con el teodolito y conocida la latitud (obtenida con el GPS), calculamos la declinación celeste ${ }^{3}(\delta)$ del astro que tiene su orto u ocaso por dicho punto a través de una sencilla ecuación de transformación de coordenadas (ecuación 5 de Esteban y Moret 2006).

\section{RESULTADOS}

En la figura 4A mostramos una vista general del santuario de entrada al oppidum del Cerro de

\footnotetext{
1 Ángulo horizontal respecto al norte geográfico.

${ }^{2}$ La brújula empleada presenta una deriva sistemática de $-1^{\circ}$ respecto a la declinación magnética que proporciona el Centro Nacional de Información Geográfica (IGN), que es de $-1^{\circ}\left(1^{\circ}\right.$ hacia el oeste) para el lugar y fecha que nos ocupan.

${ }^{3}$ La declinación corresponde al ángulo sexagesimal entre un astro y el ecuador celeste medido a lo largo del círculo máximo que pasa por los polos celestes y dicho astro. Es una de las coordenadas ecuatoriales (junto con la ascensión recta) que se utilizan para localizar los astros sobre la esfera celeste, el rango de valores posibles varía de $+90^{\circ}$ a $-90^{\circ}$.
}

las Cabezas desde el oeste donde se señalan los muros cuya orientación se midió con la brújula. Cada muro viene determinado por un número $\mathrm{y}$ una flecha. Como la dirección de un muro puede definir dos sentidos opuestos, hemos escogido siempre el que apunta a la parte despejada del horizonte, es decir, a su mitad oriental (los extremos de las flechas representadas en la figura 4 indican ese sentido). En la tabla 1 mostramos los valores de acimut correspondiente a dichas orientaciones, la altura angular del punto del horizonte hacia donde apuntan los muros (que se midió con el teodolito) y la declinación celeste del astro que tendría su orto por dichos puntos. La incertidumbre típica de las medidas es de $1^{\circ}$ en acimut, $0,1^{\circ}$ en altura y $1^{\circ}$ en declinación, en el caso del muro 5 , la incertidumbre es algo mayor (del orden de $3^{\circ}$ en declinación) porque contiene la puerta de acceso al recinto y la orientación de los dos tramos del muro a ambos lados del acceso difiere unos $2,5^{\circ}$. La incertidumbre en altura es mucho menor que en acimut debido a que la primera coordenada se midió con el teodolito y la segunda con la brújula.

El resultado más interesante de los mostrados en la tabla 1 es que los dos muros contiguos al número 3 (el que tiene adosados los tres betilos alineados) apuntan aproximadamente al orto solar en dos momentos singulares de la trayectoria anual del Sol sobre la bóveda celeste: los equinoccios (muro 2) y el solsticio de verano (muro 4). Somos conscientes que la correspondencia no es perfecta y que la diferencia es del orden de unos $2,5^{\circ}$ en declinación, aunque parece asumible si tenemos en cuenta la incertidumbre de $1^{\circ}$ de la medida de la orientación y en la precisión intrínseca de la construcción de los muros. Ambos muros parecen apuntar hacia los puntos del horizonte dónde se producen el orto solar en los equinoccios (Fig. 4B) y el solsticio de verano (Fig. 4C). En el caso de los equinoccios (o día mitad entre solsticios, véase Sección 5) podemos ver que la salida del Sol coincide con la cumbre de una pequeña loma relativamente distante y situada en el último plano del horizonte visible en esa zona, exactamente en el este geográfico. El orto del solsticio de verano no se produce por un lugar destacable como en los equinoccios, aunque coincide en una pequeña vaguada de un cerro cercano situado al noreste del yacimiento.

Una vez encontramos una relación astronómica solar plausible para dos de los muros del santua-

Trab. Prehist., 73, N. ${ }^{\circ}$ 2, julio-diciembre 2016, pp. 268-283, ISSN: 0082-5638

doi: $10.3989 /$ tp.2016.12173 

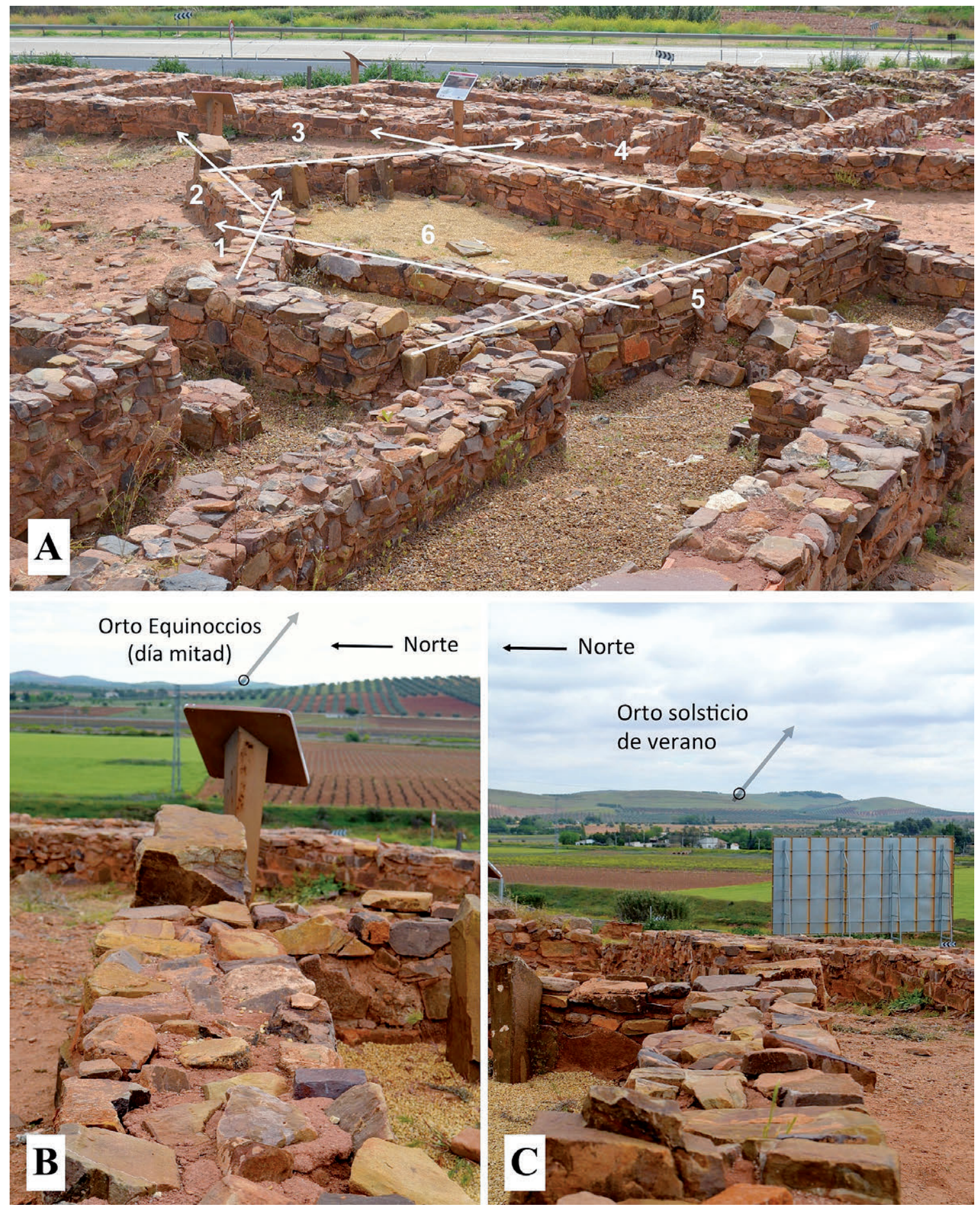

Fig. 4. Oppidum del Cerro de las Cabezas. A. Vista general del recinto del santuario de entrada tomada desde el oeste. Los números designan los distintos muros que se han considerado en este trabajo. Las flechas indican su orientación hacia levante. B. Orientación del muro 2 hacia el punto del horizonte donde se produce el orto solar en los equinoccios. C. Orientación del muro 4 hacia el punto del horizonte donde se produce el orto solar en el solsticio de verano. En B y C el círculo indica el tamaño del disco del Sol, la flecha gris inclinada señala su trayectoria y la flecha negra horizontal la dirección norte. 


\begin{tabular}{|c|c|c|c|c|}
\hline Muro & $\begin{array}{c}\text { Acimut } \\
(\mathbf{(})\end{array}$ & $\begin{array}{c}\text { Altura } \\
\left(\mathbf{(}^{\mathbf{}}\right)\end{array}$ & $\begin{array}{c}\text { Declinación } \\
\left(\mathbf{(}^{\mathbf{0}}\right.\end{array}$ & $\begin{array}{c}\text { Posible evento astronómico } \\
(\text { ortos })\end{array}$ \\
\hline 1 & 110,0 & 0,5 & $-15,2$ & $\begin{array}{c}\text { Orto solar cercano al día mitad del otoño } \\
\text { o invierno. } \\
\text { Estrella Sirio }\left(-16,3^{\circ}\right)\end{array}$ \\
\hline 2 & 87,0 & 0,1 & $+2,4$ & Equinoccios $\left(0^{\circ}\right)$ \\
\hline 3 & 168,0 & 0,6 & $-49,2$ & Estrella Hadar $\left(-49,5^{\circ}\right)$ \\
\hline 4 & 62,5 & 0,4 & $+21,4$ & Solsticio de verano $\left(+23,7^{\circ}\right)$ \\
\hline 5 & 151,0 & 0,9 & $-42,3$ & Estrella Gacrux $\left(-44,0^{\circ}\right)$ \\
\hline 6 & 46,0 & 1,1 & $+33,7$ & Estrella Arturo $\left(+32,7^{\circ}\right)$ \\
\hline
\end{tabular}

Tab. 1. Orientaciones de los muros del santuario de entrada del oppidum Cerro de las Cabezas (Valdepeñas, Ciudad Real) y su posible relación astronómica según la hipótesis de máximos.

rio de entrada parece pertinente preguntarse ¿qué ocurre con el resto de los muros del edificio? Una primera hipótesis de trabajo es suponer que la orientación de todos los muros perimetrales tuvieron una motivación astronómica. Excepto los muros 1, 2 y 4, el resto no presenta relaciones con ortos solares, lunares o planetarios. La declinación correspondiente al muro 1 es de $-15,2^{\circ}$ y podría corresponder (en el año de referencia 350 a.C. que hemos escogido como representativo de la cronología del yacimiento) al orto solar en una fecha de comienzos de noviembre o principios de febrero, muy cercana (unos pocos días después o antes) al día mitad de estación entre el equinoccio de otoño y el solsticio de invierno o entre éste último y el equinoccio de primavera ${ }^{4}$. Indagando posibles relaciones con estrellas ${ }^{5}$ vimos una muy interesante entre el muro $1 \mathrm{y}$ el orto de la estre1la Sirio ( $\alpha$ Canis Maioris), la más brillante del cielo, que tenía una declinación de $-16,3^{\circ}$ en el año 350 a.C., consistente con la orientación del muro dentro de las incertidumbres. Alentados por esta posible orientación estelar, comparamos las declinaciones de las estrellas más brillantes en el año 350 a.C. y las definidas por las orientaciones del resto de los muros, encontrando que el número 6 ajusta con la posición del orto de la estrella

\footnotetext{
${ }^{4}$ En ese día mitad del otoño o del invierno la declinación solar sería de $-13,5^{\circ}$.

${ }^{5}$ Para ello consultamos el trabajo de Hawkins y Rosenthal (1967) que calcula la posición de las estrellas más brillantes de magnitud visual 3 (un total de 144) desde el 2500 a.C hasta el 2500 d.C. en intervalos de 100 años, teniendo en cuenta la precesión de los equinoccios y el movimiento propio de cada estrella.
}

Arturo ( $\alpha$ Bootis $\left.,+32,7^{\circ}\right)$, la segunda estrella más brillante (detrás de Sirio) para los observadores situados a la latitud del Cerro de las Cabezas ${ }^{6}$. Los muros 3 y 5 apuntan muy hacia el sur, hacia una zona donde se levantaban algunas estrellas relevantes que marcaban las cercanías del punto cardinal sur. El orto de Hadar ( $\beta$ Centauri), la décima estrella más brillante del firmamento (declinación de $-49,5^{\circ}$ en el 350 a.C.) parece ajustar bien la orientación del muro 3 y es la más brillante que podían observar los habitantes de la Oretania en aquella zona tan meridional del cielo. El problema con esta estrella es que apenas se levantaría unos $2^{\circ}$ como máximo sobre el horizonte $y$, aunque su magnitud visual es de $+0,60$, su visibilidad dependería mucho de las condiciones atmosféricas y de la proporción de polvo en la atmósfera. Por otra parte sólo sería visible por encima del horizonte durante un mes aproximadamente. Finalmente, el muro 5 podría apuntar a la estrella Gacrux ( $\gamma$ Crucis), la estrella del extremo septentrional de la constelación de la Cruz del Sur, la vigesimosexta estrella más brillante del firmamento y que llegaría a alcanzar una altura máxima de $9^{\circ}$ sobre el horizonte.

Es posible que el lector considere que la hipótesis de máximos que hemos planteado (todos los muros tienen una relación astronómica) y que resumimos en la tabla 1 sea demasiado forzada. Es una objeción razonable, aunque los resultados

\footnotetext{
${ }^{6}$ La segunda estrella más brillante del cielo es Canopus, $(\alpha$ Carinae) pero no era visible por encima del horizonte oretano en la época considerada.
} 
de esta hipótesis resultan bastante sorprendentes, porque están involucrados los ortos de dos posiciones singulares (de tres posibles) del movimiento anuo solar, las dos estrellas más brillantes del firmamento a la latitud de Cerro de las Cabezas y dos de las estrellas más brillantes que se podían observar en el extremo meridional de la bóveda celeste, muy cerca del punto cardinal sur. De cualquier manera, podemos plantear una hipótesis más relajada suponiendo que no todos los muros del santuario tienen por qué presentar una relación astronómica y que la disposición de algunos de ellos está condicionada por otros factores como la orientación urbana definida por el resto de los edificios. Bajo este supuesto aplicamos el criterio de desechar aquellas relaciones definidas por los muros medianeros con otras estancias vecinas, por lo que podríamos ignorar las relaciones de los muros 1,5 y 6 . Esta segunda hipótesis nos deja las mismas relaciones solares y una estelar para el muro 3 (con el orto de Hadar, $\beta$ Centauri, muy cercano al punto cardinal sur). Una tercera hipó- tesis, que denominamos "de mínimos", supondría el asumir únicamente relaciones solares en el santuario de entrada del Cerro de las Cabezas, por lo que sólo las orientaciones de los muros 2 y 4 serían relevantes. Esta hipótesis supondría asumir que la relación astronómica del muro 3 es fortuita y que este muro se orienta simplemente para unir las paredes 2 y 4 . Discutiremos la verosimilitud y las implicaciones de cada una de estas hipótesis en la sección 5.

Un resultado adicional de nuestro estudio es el descubrimiento de una posible alineación con interés astronómico entre el santuario de entrada, el área junto al oppidum donde se encontró la necrópolis del poblado (Poveda y Benítez de Lugo 2015; Benítez de Lugo et al. e. p.) y el punto donde se observa el orto solar en el solsticio de invierno desde el propio santuario (Fig. 5A). Hay que hace notar que la extensión total de la necrópolis es desconocida y que el área excavada es todavía muy limitada $\left(56,88 \mathrm{~m}^{2}\right.$; catorce tumbas encontradas en catorce días de excavación

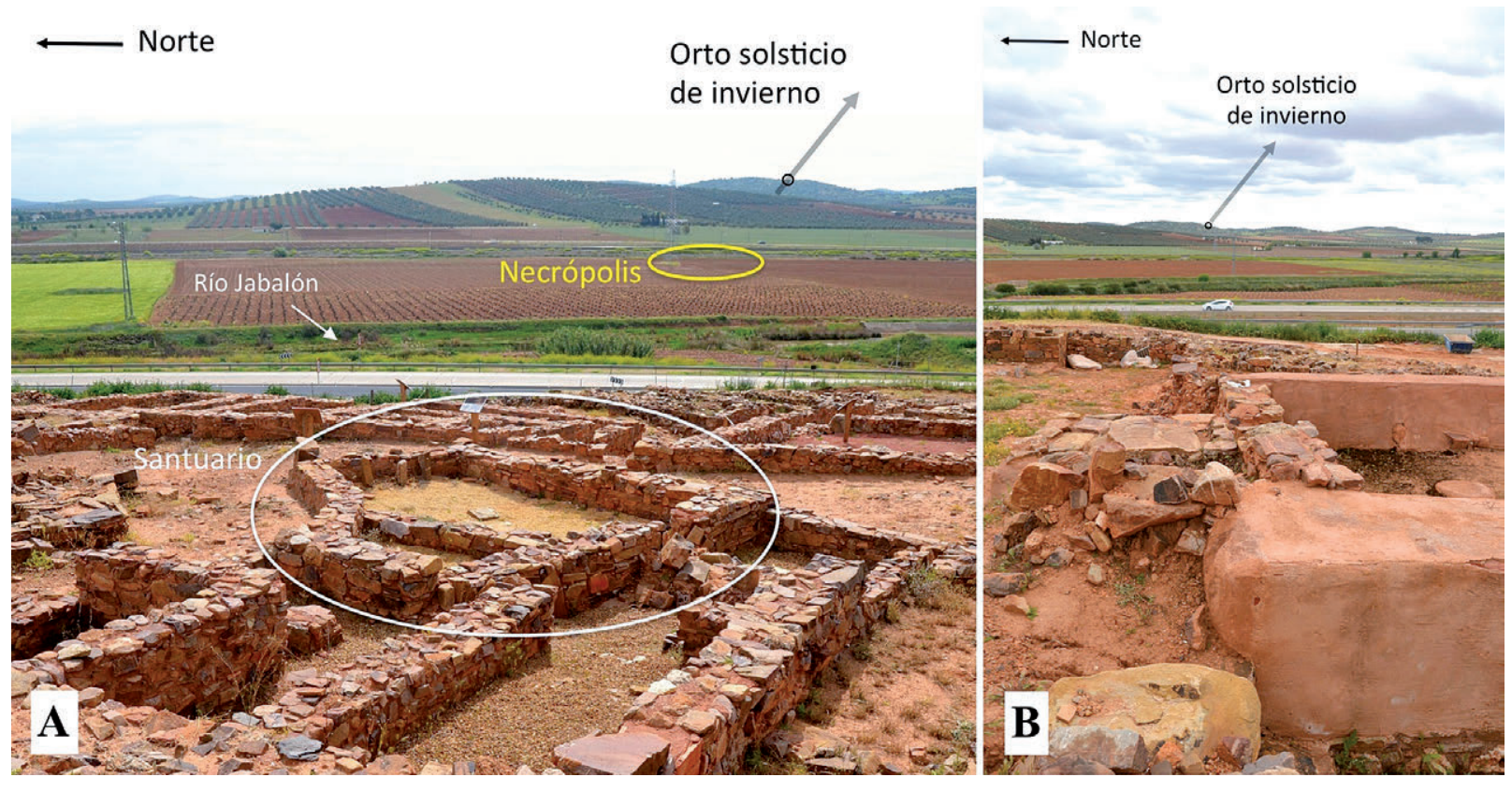

Fig. 5. Oppidum de Cerro de las Cabezas. A. Vista general del horizonte este-sureste desde el área del santuario de entrada. Se delimita la posición del santuario respecto a los restos encontrados de la necrópolis. La imagen muestra gráficamente el alineamiento del santuario, la necrópolis y el orto solsticial. Se indica también el cauce del río Jabalón, situado entre el oppidum y la necrópolis. B. Orientación del muro norte del recinto del bastión sur del oppidum que ha sido interpretado como santuario. En ambas imágenes, el pequeño círculo indica el punto del horizonte por donde se produce el orto solar en el solsticio de invierno. Su tamaño coincide con el del disco del Sol. La flecha gris inclinada señala su trayectoria y la flecha negra horizontal la dirección norte. 
arqueológica), por lo que la presunta orientación tendría que interpretarse desde un punto de vista simbólico donde la precisión no sería un factor relevante. Con la inclusión de esta tercera relación solar en el santuario de entrada tendríamos que todas las posiciones singulares del movimiento anuo del Sol: equinoccios y ambos solsticios, están representados de alguna forma en el edificio.

Por último, realizamos medidas del recinto adosado por el este al bastión sur del poblado, cuya discutible interpretación como "Santuario Sur" (Vélez y Pérez Avilés 2008, 2010: 29) ya se ha comentado (García Huerta y Morales 2009: 183; Benítez de Lugo y Moraleda 2013: 233-234). Medimos la orientación de sus muros este, oeste y norte, comprobando que los dos primeros son casi perfectamente paralelos (acimut de $29^{\circ}$ y $30^{\circ}$, respectivamente), apuntando sobre el horizonte oriental hacia el punto donde se produce el orto de un astro con declinación $+43,5^{\circ}$, que no coincide con ningún objeto del Sistema Solar ni con ninguna estrella brillante (con un brillo superior a la magnitud visual de 3,0). Por otro lado, la pared norte presenta un acimut de $117^{\circ}$ $\mathrm{y}$, hacia el oriente, apunta al orto de un astro con declinación $-20,5^{\circ}$, unos $3^{\circ}$ al norte del solsticio de invierno (Fig. 5B) por lo que podría proponerse una posible relación con este evento astronómico. Es necesario indicar que el recinto comparte esta orientación general con buena parte de las construcciones de esta zona del poblado (Fig. 3B). En particular, el bastión sur así como el gran almacén (horrea, indicado como edificio rectangular en figura 3B) adyacente presentan exactamente la misma disposición espacial. Esta característica es una diferencia importante respecto al santuario de entrada donde la orientación de los muros, en general, varía respecto a la de la trama urbana del resto de las manzanas vecinas (Fig. 3A). La edificación aneja al gran almacén situada dentro del bastión sur no puede, por tanto, ser considerada como edificio singular en base a su orientación astronómica.

\section{DISCUSIÓN}

Como vimos en la sección anterior, el santuario de entrada del Cerro de las Cabezas tiene un gran potencial arqueoastronómico, incluso con- siderando únicamente las orientaciones solares (nuestra hipótesis de mínimos). Orientaciones simultáneas de elementos arquitectónicos hacia dos momentos singulares del movimiento anuo solar es algo de lo que no tenemos precedente en los estudios arqueoastronómicos realizados sobre la cultura ibérica. Los únicos ejemplos de posible relación astronómica de un yacimiento ibérico con los equinoccios y alguno de los solsticios están basados en la presencia de marcadores astronómicos sobre el horizonte, pero no en la orientación de muros de edificaciones, como es el caso estudiado. La relación aludida se constata en los santuarios también oretanos de El Pajarillo (Huelma, Jaén) y Torreparedones (Castro del Río-Baena, Córdoba; Morena López y Abril Hernández 2013) donde el solsticio marcado es el de invierno: el orto en Torreparedones y el ocaso en El Pajarillo.

El hecho de que el orto de los equinoccios se produzca sobre la parte superior de uno de los cerros $^{7}$ más lejanos que se divisan desde Cerro de las Cabezas, lo incluye en la ya larga lista de santuarios ibéricos que muestran marcadores de este evento solar y que se extienden por buena parte del territorio ocupado por dicha cultura, desde la Oretania en el sur hasta la Edetania y el Bajo Aragón por el norte. Esteban (2013) ha revisado las características de este tipo de marcadores, cuyo elemento principal es que el orto solar en los equinoccios (o el día mitad entre solsticios) se produce sobre la cumbre de una montaña generalmente lejana y conspicua del horizonte. El grado de espectacularidad del fenómeno varía de un yacimiento a otro. En La Malladeta (La Vila Joiosa, Alicante) o El Amarejo (Bonete, Albacete; Esteban 2002) los elementos topográficos que producen el marcador (islote en el primer caso y montaña en el segundo) son muy llamativos y únicos en el horizonte oriental, sugiriendo que el orto equinoccial podría haber sido utilizado como un elemento ritual de dimensión pública. Sin embargo, la mayoría de las veces, la montaña donde se produce el orto $u$ ocaso equinoccial suele ser lejana y no especialmente conspicua, lo que apunta a una posible utilidad como marcador calendárico, como jalón para calibrar el calendario solar por parte de los posibles encargados del culto o

\footnotetext{
${ }^{7}$ Cerro Córcobo, con una altitud ortométrica de $828 \mathrm{~m} \mathrm{y}$ situado a 9,7 km de distancia del Cerro de las Cabezas.
}

Trab. Prehist., 73, N. ${ }^{\circ}$ 2, julio-diciembre 2016, pp. 268-283, ISSN: 0082-5638

doi: $10.3989 /$ tp.2016.12173 
sacerdotes ${ }^{8}$. En el caso del Cerro de las Cabezas, nuestras medidas con el teodolito indican que la cumbre del cerro Córcobo corresponde a una declinación de $0,25^{\circ} \pm 0,15^{\circ}$. Desgraciadamente, este valor no nos permite discriminar si era el equinoccio o el día mitad entre solsticios el evento astronómico que daba sentido al marcador ${ }^{9}$ pues está justo entre ambas posiciones solares. Por definición, el equinoccio astronómico corresponde a una declinación de $0^{\circ}$, mientras que el día mitad entre solsticios está en el rango $0,7^{\circ} \pm 0,3^{\circ}$ (Esteban 2013). Teniendo en cuenta que el diámetro del disco solar es de unos $0,5^{\circ}$, tanto el borde norte del disco durante el orto más cercano a los equinoccios, como el borde sur en el orto correspondiente al día mitad tocaría la cumbre del Córcobo. Como este cerro es ancho y redondeado y la parte más elevada está situada hacia el borde sur del cerro, si consideramos su parte central (que presenta una anchura de unos $1,5^{\circ}$ ) como referencia del marcador, sería más consistente con el día mitad, como ocurre en la hierofanía solar de la cuevasantuario de Castellar (Esteban et al. 2014) o en el espectacular marcador de La Malladeta.

Orientaciones hacia el orto del solsticio de verano no son comunes en los santuarios ibéricos. El ejemplo más claro en este sentido es el templo de la acrópolis ${ }^{10}$ de Ullastret (Girona), cuyo eje mayor y puerta de acceso apuntan con bastante precisión hacia el orto solar en el solsticio de verano (Esteban 2002). Otro caso más cercano es el santuario de La Escuera (San Fulgencio, Alicante) donde uno de los dos ejes del edificio se encuentra orientado a lo largo de la línea definida por el orto

\footnotetext{
${ }^{8}$ Las claras relaciones astronómicas que presentan un número cada vez mayor de santuarios ibéricos hace razonable plantear la existencia de un personal especializado encargado del seguimiento periódico de la posición del Sol y quizás de otros astros.

${ }^{9}$ Como ya se ha discutido en distintos trabajos (Esteban 2002, 2013; Esteban et al. 2014), el equinoccio astronómico es un concepto geométrico y abstracto que quizás ni fuera conocido por los iberos y probablemente careciera de utilidad práctica para ellos. Por el contrario, el concepto día mitad entre el solsticio de verano y el de invierno es mucho más concreto y coincidiría igualmente con el cambio estacional. Ambos eventos ocurren con una separación del orden de dos días por lo que la posición del Sol no es muy diferente.

${ }^{10}$ En esta zona más alta del poblado del Puig de Sant Andreu se han documentado dos templos, el que consideramos aquí es el mejor conservado y mas meridional, se trata de un templo in antis con cella de planta cuadrangular, fechado en el siglo III a.C. (Moneo 2003: 229-230).
}

del solsticio de verano y el ocaso del solsticio de invierno (Esteban 2002). Sin embargo, las últimas investigaciones arqueoastronómicas en el área andaluza sugieren que los marcadores y orientaciones hacia el orto del solsticio de verano pudieron ser un rasgo habitual en templos y santuarios de época orientalizante y en las zonas de posterior influencia púnica de la Península Ibérica. Escacena Carrasco $(2007,2009)$ ya indicó la posibilidad de rituales solares relacionados con el orto del solsticio de verano y la festividad de resurrección del dios Baal atendiendo a la orientación de los santuarios y altares con forma de piel de toro de El Carambolo (Camas, Sevilla) y el Cerro de San Juan (Coria del Río, Sevilla). Datos muy recientes de otros yacimientos de época orientalizante como los edificios de la acrópolis de Castillejos de Alcorrín (Manilva, Málaga) y de ambientes de fuerte influencia púnica como los santuarios de la Muela de Cástulo (Linares, Jaén) o el de Mijas (Málaga) presentan posibles marcadores del orto del solsticio de verano sobre elementos topográficos del horizonte. Un precedente de esta costumbre solsticial podríamos tenerla en el templo dedicado a Baal de Pella, en el valle del Jordán (Jordania), donde Polcaro et al. (2013) constatan que su eje mayor y la entrada se encuentra orientado hacia la salida del Sol en el solsticio de verano. Las evidencias citadas parecen sugerir la pervivencia de elementos solares de posible origen oriental en el ritual de los habitantes ibéricos de Cerro de las Cabezas. Como ya se comentó anteriormente, El Pajarillo y Torreparedones, los únicos santuarios ibéricos conocidos con relaciones astronómicas dobles equinoccio-solsticio, también están localizados en Oretania, por lo que cabe la posibilidad de que estemos ante una costumbre de orientación ritual solar característica de la zona.

Hemos apuntado un posible origen oriental a las relaciones astronómicas encontradas en el Cerro de las Cabezas, pero tampoco podemos excluir que fueran producto de tradiciones de las culturas que poblaron con anterioridad el territorio oretano. Se ha medido la orientación de casi un millar de monumentos funerarios megalíticos en la Península Ibérica (con cronologías que van desde el final del Neolítico hasta la Edad del Bronce) y la mayor parte de ellos, sobre todo los del sur y oeste peninsular, apuntan sistemáticamente hacia los puntos del horizonte donde se producen los ortos solares o lunares a lo largo del año (por ejemplo Hoskin 2001; 
Belmonte y Hoskin 2002). En particular, estudios recientes sobre el complejo funerario tumular del Castillejo del Bonete (Terrinches, Ciudad Real), fechado en el último cuarto del III milenio a.C., y de otros yacimientos adscritos al mismo horizonte cultural, indican la existencia de marcadores y orientaciones hacia los ortos y ocasos solares en los solsticios ya durante la Prehistoria Reciente en la Meseta Sur (Benítez de Lugo et al. 2014; Esteban 2015; Esteban y Benítez de Lugo e. p.).

Nuestra hipótesis arqueoastronómica de máximos, el considerar deliberadas las orientaciones estelares de algunos de los muros del santuario de entrada, plantea el problema de que no está bien establecida la existencia de orientaciones hacia estrellas en el mundo ibérico, principalmente porque es difícil argumentarlas. En primer lugar, la posición sobre la esfera celeste de las estrellas (es decir, sus coordenadas, entre ellas la declinación) cambia de forma significativa a lo largo de los siglos debido a la precesión de los equinoccios (cosa que no afecta a la posición del Sol y la Luna) y, por lo tanto, debemos disponer de una datación confiable del yacimiento para fijar las coordenadas estelares con las que comparar nuestras orientaciones. Otra dificultad es la gran cantidad de estrellas visibles a simple vista en el cielo (alrededor de unas 2000) que hacen que siempre podamos encontrar alguna que coincida con la orientación que midamos aunque, bien es cierto, si nos limitamos a las más brillantes dicha probabilidad disminuye. Un último motivo es que la extinción que produce la atmósfera a bajas alturas sobre el horizonte (variable según las condiciones meteorológicas locales) dificulta e incluso imposibilita observar el orto u ocaso de estrellas que no sean muy brillantes. En el caso de las orientaciones estelares que encontramos para algunos muros del santuario de entrada, tenemos la ventaja de que corresponden con estrellas muy brillantes cuyo orto se puede observar en condiciones atmosféricas normales. Por otra parte también disponemos de cronología en el yacimiento, por lo que creemos que las orientaciones estelares en nuestra hipótesis de máximos son plausibles.

Pérez Gutiérrez et al. (2011) estudiaron la orientación del edificio cultual del Turó del Calvari (Vilalba dels Arcs, Tarragona), datado a comienzos de la Edad del Hierro (siglos VII-VI a.C., Bea Castaño y Diloli Fons 2005), encontrando que su eje principal se orienta hacia el ocaso de la estrella
Arturo (a Bootis), como ya se ha dicho, la segunda estrella más brillante del cielo visible desde las latitudes ibéricas. Según estos autores, la relación del edificio con Arturo podría deberse a que los ortos y ocasos helíacos ${ }^{11}$ de esta estrella, según Hesíodo en Los trabajos y los días, indicaban momentos del ciclo agrícola de la vid. Es interesante recordar que el muro 6 del santuario de entrada del Cerro de las Cabezas apunta hacia el orto de Arturo. Según Hesíodo, en sus tiempos (circa 700 a.C.), el orto helíaco de esta estrella indicaba el momento de la vendimia, en nuestro mes actual de septiembre, hecho todavía válido en época ibérica. En este punto cabe recordar que Valdepeñas es conocida como "Ciudad del vino" y que La Mancha es el territorio vitivinícola más extenso del mundo. Podría tratarse, por tanto, de una primera indicación del cultivo de la vid en este territorio.

En la sección 4 advertimos que el recinto adosado al bastión sur del poblado e interpretado como santuario podría tener un eje orientado aproximadamente hacia el orto del solsticio de invierno (Fig. 5B). Ya comentamos que, a diferencia del santuario de entrada, todos los muros de este edificio comparten exactamente la orientación de la trama urbana de esa zona del poblado y también de la muralla perimetral meridional (Fig. 3B). En nuestra opinión, la posible orientación solsticial de esta zona del poblado se podría deber a dos motivos: simple casualidad o una posible orientación de tipo augural, relacionada con la fundación de edificaciones en el oppidum. En este sentido, las ofrendas halladas en la esquina suroeste del recinto y que han sido interpretadas como producto de un rito fundacional (Vélez y Pérez Avilés 2009) podrían apoyar esta segunda posibilidad. Las posibles orientaciones astronómicas de los depósitos fundacionales en época ibérica o del urbanismo oretano están todavía insuficientemente estudiadas.

Otro aspecto a discutir es el aparente alineamiento entre el santuario de entrada del Cerro de las Cabezas, la necrópolis y el punto donde se produce el orto solar en el solsticio de invierno (Fig. 5A). La eventual relación astronómica de la disposición relativa entre yacimientos ibéricos tampoco se ha explorado de forma sistemática.

\footnotetext{
${ }^{11}$ Orto helíaco es el primer día del año en que la salida de un astro es visible en el crepúsculo de la mañana, antes del orto solar. Ocaso helíaco es la última puesta de un astro visible después del crepúsculo vespertino.
} 
Esteban (2002) identificó un posible ejemplo en la necrópolis de Cabezo Lucero (Guardamar del Segura-Rojales, Alicante). Allí existe un cierto alineamiento con el cerro conocido como Cabezo Soler, donde se produce el ocaso equinoccial (visto desde la necrópolis) y con el promontorio costero en el que se localizaba el santuario del Castillo de Guardamar, cercano al punto de observación del amanecer equinoccial desde las tumbas de la necrópolis que, por otro lado, muestran una orientación sistemática este-oeste. Nótese que en ambos ejemplos, Cerro de las Cabezas y Cabezo Lucero, se alinea un conjunto similar de elementos: santuario, necrópolis y punto singular de orto u ocaso solar. Ello sugiere que hubiera entre los iberos una posible costumbre de ubicar los recintos cultuales y funerarios a lo largo de líneas de significación solar.

Un último aspecto importante a discutir es que las líneas de visión definidas por los distintos muros, tanto en el santuario de entrada como en el edificio del bastión sur, podrían haber estado bloqueadas por otras construcciones. En las figuras $4 \mathrm{~B}$ a $5 \mathrm{~B}$ podemos ver que muros de otros edificios colindantes y las propias murallas del oppidum interfieren con la visión de los ortos asociados a las alineaciones astronómicas propuestas. Esto plantea una duda razonable sobre la utilidad práctica de unas líneas de visión cegadas. Este hecho contrasta con lo que se ve en el santuario ibérico del Tossal de Sant Miquel de Llíria (Esteban y Moret 2006), situado también en el interior de un poblado, y cuyo alineamiento y marcador equinoccial se asemeja al que define el muro 2 del santuario de entrada de Cerro de las Cabezas. Al contrario que en el santuario oretano, el edifico de Llíria está situado en una zona alta del poblado y con un área libre de edificaciones hacia el este, lo que implica que la línea de visión estaba muy probablemente despejada, garantizando la observación del orto equinoccial. La orientación del edificio anejo al bastión sur de Cerro de las Cabezas, consistente con el resto de estructuras adyacentes, y su posible motivación augural hacen que la visión del fenómeno astronómico asociado no sea un requerimiento que pueda considerarse necesario. Sin embargo, en el santuario de entrada, la presencia de un marcador equinoccial invisible desde el edificio resulta paradójica. Tal vez este hecho podría deberse a que la elección del em- plazamiento (frente a la puerta septentrional de la ciudad y por la presencia del marcador) y el diseño del santuario (orientación astronómica de los muros) precedieron a la construcción de las estructuras colindantes hacia el este, y a que las orientaciones astronómicas del edificio dejaran de tener una utilidad práctica para convertirse en puramente simbólicas.

\section{CONCLUSIONES}

El presente estudio revela la existencia de orientaciones astronómicas en el santuario de entrada situado frente a la puerta septentrional del oppidum oretano Cerro de las Cabezas. Dos de los muros principales de este edificio se orientan, respectivamente, hacia la salida del Sol en los equinoccios y en el solsticio del verano. La relación equinoccial se ve reforzada con el descubrimiento de que el orto solar en dicho momento del año se produce sobre una de las montañas más lejanas visibles desde el yacimiento: el cerro Córcobo. Los restantes muros podrían estar orientados hacia los ortos de algunas de las estrellas más brillantes del cielo, como Arturo, Sirio, y otras situadas en el hemisferio sur e invisibles en la actualidad. Se ha hallado una alineación astronómica entre el santuario de entrada, la necrópolis situada extramuros a unos $200 \mathrm{~m}$ al este del poblado, y el punto donde se observa el orto solar en el solsticio de invierno desde el propio santuario. Este último resultado implica que todas las posiciones singulares del movimiento anuo del Sol -equinoccios y ambos solsticios- están representados de alguna forma en el edificio. Nos parece significativo que orientaciones o marcadores dobles hacia el orto u ocaso en el equinoccio y el solsticio de invierno sólo se han encontrado en otros santuarios oretanos, como El Pajarillo o Torreparedones.

Por contra, las orientaciones del edificio denominado por sus excavadores "Santuario Sur" no difieren de las de otras construcciones adyacentes. Sin embargo, su eje este-oeste, común al resto de edificios de esta zona del oppidum, podría apuntar (con una baja precisión) al orto solar en el solsticio de invierno. Se sugiere que esta posible relación astronómica podría estar relacionada con algún rito fundacional. 


\section{BIBLIOGRAFÍA}

Almagro Gorbea, M. y Moneo, T. 2000: Santuarios urbanos en el mundo ibérico. Real Academia de la Historia. Madrid.

Bea Castaño, D. y Diloli Fons, J. 2005: "Elements de representació durant la Primera Edat del Ferro al curs inferior de l'Ebre: el recinte del Turoó del Calvari (Vilalba dels Arcs, Terra Alta)". Revista d'Arqueologia de Ponent 15: 179-198.

Belmonte, J. A. y Hoskin, M. 2002: Reflejo del Cosmos. Atlas de arqueoastronomía del Mediterráneo antiguo. Equipo Sirius. Madrid.

Benítez de Lugo, L. 2004: "La Arqueología del Culto ibérica en la Oretania septentrional". Arse 38: 29-62.

Benítez de Lugo, L.; Esteban, G. y Hevia, P. 2004: Protohistoria y Antigüedad en la provincia de Ciudad Real (800 a.C.-500 d.C.). C\&G. Ciudad Real.

Benítez de Lugo Enrich, L.; Álvarez García, H. J.; Fernández Martín, S.; Mata Trujillo, E.; Moraleda Sierra, J.; Palomares Zumajo, N.; Odriozola Lloret, C.; Morgado Rodríguez, A. y Salazar-García, D. C. 2014: "Castillejo del Bonete (Terrinches, Ciudad Real, España): un complejo tumular prehistórico de la Cultura de las Motillas en el Alto Guadalquivir". Menga. Revista de Prehistoria de Andalucía 5: 151-173.

Benítez de Lugo Enrich, L. y Moraleda Sierra, J. 2013: "Símbolos, espacios y elementos ibéricos para el culto en Oretania septentrional. Estado de la cuestión arqueológica, revisión crítica y nuevas aportaciones". En C. Rísquez y C. Rueda (eds.): Santuarios iberos: territorio, ritualidad y memoria. Actas del Congreso El Santuario de la Cueva de La Lobera de Castellar (Jaén) 1912-2012 (Castellar, Jaén 2012): 213-269. Jaén.

Benítez de Lugo Enrich, L.; Poveda Navarro, A. M.; Urbina Martínez, D. y Urquijo Álvarez de Toledo, C. en prensa: "Romanización de rituales funerarios oretanos: la Tumba 1 del oppidum Cerro de las Cabezas (Valdepeñas, Ciudad Real)". Saguntum 2016 (48).

Carmona Astillero, M. 2003: "Tratamientos realizados en el Santuario Sur del Cerro de las Cabezas". Cuadernos de Estudios Manchegos 25-26: 49-77.

Escacena Carrasco, J. L. 2007: "El dios que resucita: claves de un mito en su primer viaje a Occidente". En J. J. Justel, B. E. Solans, J. P. Vita y J. Á. Zamora (eds.): Las aguas primigenias. El Próximo Oriente Antiguo como fuente de civilización, Actas del IV Congreso Español de Antiguo Oriente Próximo. 615-651. Zaragoza.

Escacena Carrasco, J. L. 2009: "La Égersis de Melqart. Hipótesis sobre una teología solar cananea". Complutum 20 (2): 95-120.

Esteban, C. 2002: "Elementos astronómicos en el mundo religioso y funerario ibérico". Trabajos de Prehistoria 59 (2): 81-100.
Esteban, C. 2013: “Arqueoastronomía y religión ibérica”. En C. Rísquez y C. Rueda (eds.): Santuarios iberos: territorio, ritualidad y memoria. Actas del Congreso El Santuario de la Cueva de La Lobera de Castellar (Jaén) 1912-2012 (Castellar, Jaén 2012). 465-489. Jaén.

Esteban, C. 2015: "Astros y mundo funerario en el Bronce de La Mancha”. M. Mejías, L. Benítez de Lugo, J. A. López-Sáez y C. Esteban (eds.): Arqueología, Hidrogeología y Medio Ambiente en la Edad del Bronce de La Mancha: la Cultura de Las Motillas. Instituto Geológico y Minero de España. Madrid: 83-93.

Esteban, C. y Benítez de Lugo Enrich, L. en prensa: "Archaeoastronomy in Bronze Age Sites of La Mancha (Spain)". Mediterranean Archaeology and Archaeometry, 2016.

Esteban, C. y Escacena Carrasco, J. L. 2013: Arqueología del cielo. Orientaciones astronómicas en edificios protohistóricos del sur de la Península Ibérica", Trabajos de Prehistoria 71 (1): 113-138.

Esteban, C. y Moret, S. 2006: "Ciclos de tiempo en la cultura ibérica: la orientación astronómica del Templo del Tossal de Sant Miquel de Llíria”. Trabajos de Prehistoria 63 (1): 167-178.

Esteban, C.; Rísquez, C. y Rueda, C. 2014: "Una hierofanía solar en el santuario ibérico de Castellar (Jaén)". Archivo Español de Arqueología 87: 91-107.

García Huerta, R. y Morales, F. J. 2009: "Sistema de almacenamiento y tratamiento de alimentos entre los pueblos prerromanos de la Meseta meridional". En R. García y D. Rodríguez (eds.): Sistemas de almacenamiento entre los pueblos prerromanos peninsulares. Universidad de Castilla-La Mancha. Cuenca: 167-207.

Hawkins, G. S. y Rosenthal, S. K. 1967: " 5,000 - and 10,000-Year Star Catalogs". Smithsonian Contributions to Astrophysics 10: 141-179.

Hoskin, M. 2001: Tombs, temples and their orientations. Ocarina Books. Bognor Regis.

Moneo, T. 2003: Religio Iberica. Santuarios, ritos y divinidades (siglos VII-I a. C.). Real Academia de la Historia. Madrid.

Moneo, T.; Pérez, J. y Vélez, J. 2001: “Un santuario de entrada ibérico en 'El Cerro de las Cabezas' (Valdepeñas, Ciudad Real)". Complutum 12: 123-136.

Morena López, J. A. y Abril Hernández, J. M. 2013: "Estudio arqueoastronómico del santuario ibero-romano de Torreparedones (Baena, Córdoba)". Cuadernos de Prehistoria y Arqueología de la Universidad de Granada 23: 293-321.

Pérez Gutiérrez, M.; Diloli Fons, J.; Bea Castaño, D. y Sardà Seuma, S. 2011: "Astronomy, culture and landscape in the early Iron Age in the Ebro Basin". En C. L. N. Ruggles (ed.): Archaeoastronomy and ethnoastronomy: building bridges between cultures: proceedings of the $278^{\text {th }}$ Symposium of the International Astronomical Union and 'Oxford IX' Inter-

Trab. Prehist., 73, N. ${ }^{\circ}$ 2, julio-diciembre 2016, pp. 268-283, ISSN: 0082-5638

doi: $10.3989 /$ tp.2016.12173 
national Symposium on Archaeoastronomy (Lima 2011): 382-389. Cambridge.

Polcaro, A.; González-García, A. C. y Belmonte, J. A. 2013: "The orientation of the Bronze Age temple of Pella, Jordan: the dying god Baal and the rituals of the summer solstice". Anthropological Notebooks 19 (Supplement): 481-492.

Poveda Navarro, A. M. y Benítez de Lugo, L. 2015: "Nuevo ejemplo del uso de Sigillata Itálica en rituales funerarios oretanos. La tumba 1 del oppidum Cerro de las Cabezas (Valdepeñas, Ciudad Real)". Boletín Ex Officina Hispana 6: 6-9.

Rodríguez López-Cano, D. y Palencia García, J. F. 2014: "Urna de cerámica estampillada del Cerro de las Cabezas (Valdepeñas, Ciudad Real) aparecida en Madridejos (Toledo)". Boletín Ex Officina Hispana 5: 13-14.

Vélez, J. y Pérez Avilés, J. 2008: “Un espacio de culto del siglo $\mathrm{V}$ en el Cerro de las Cabezas (Valdepeñas,
Ciudad Real'. En J. Jiménez Ávila (ed.): Sidereum Ana I. El río Guadiana en época postorientalizante. Anejos de Archivo Español de Arqueología XLVI, Instituto de Arqueología de Mérida. CSIC. Mérida: 37-60.

Vélez, J. y Pérez Avilés, J. 2009: “El bastión almacén del Cerro de las Cabezas (Valdepeñas, Ciudad Real)". En R. García y D. Rodríguez (eds.): Sistemas de almacenamiento entre los pueblos prerromanos peninsulares. Universidad de Castilla-La Mancha. Cuenca: 241-256.

Vélez, J. y Pérez Avilés, J. 2010: "El oppidum ibérico del Cerro de las Cabezas. Estructuras de culto (Valdepeñas, Ciudad Real'. En T. Tortosa, S. Celestino y R. Cazorla (eds.): Debate en torno a la religiosidad protohistórica. Anejos de Archivo Español de Arqueología LV, Instituto de Arqueología de Mérida, CSIC. Madrid: 21-36. 